\title{
Cyclic Nucleotide-Gated Channels Contribute to the Cholinergic Plateau Potential in Hippocampal CA1 Pyramidal Neurons
}

\author{
J. Brent Kuzmiski and Brian A. MacVicar \\ Neuroscience Research Group, Department of Physiology and Biophysics, University of Calgary, Calgary, Alberta \\ T2N 4N1, Canada
}

\begin{abstract}
Plateau potentials are prolonged membrane depolarizations that are observed in hippocampal pyramidal neurons when spiking and $\mathrm{Ca}^{2+}$ entry occur in combination with muscarinic receptor activation. In this study, we used whole-cell voltage clamping to study the current underlying the plateau potential and to determine the cellular signaling pathways contributing to this current. When combined with muscarinic stimulation, depolarizing command potentials that evoked $\mathrm{Ca}^{2+}$ influx elicited a prolonged tail current $\left(I_{\text {tail }}\right)$ that had an extrapolated reversal potential of $-20 \mathrm{mV}$. I tail was not observed when intracellular $\mathrm{Ca}^{2+}$ levels were chelated with $10 \mathrm{~mm}$ intracellular BAPTA, and $I_{\text {tail }}$ was reversibly depressed in low external sodium. When $I_{\text {tail }}$ was evoked at intervals $>3 \mathrm{~min}$, current amplitudes were stable for up to $1 \mathrm{hr}$. However, at shorter intervals, $I_{\text {tail }}$ was refractory, with a time constant of recovery of $43.5 \mathrm{sec}$. The inhibitors of soluble guanylate cyclase $1 \mathrm{H}-[1,2,4]$ oxadiazolo[4,3-a]quinox-
\end{abstract}

alin-1-one and 6-anilino-5,8-quinolinequinone depressed $I_{\text {tail }}$ and zaprinast, which blocks cGMP-specific phosphodiesterase, enhanced $I_{\text {tail }}$, suggesting that a component of $I_{\text {tail }}$ was activated by cGMP. The inhibitors of cyclic nucleotide-gated (CNG) channels L-cis-diltiazem and 2',4'-dichlorobenzamil reversibly depressed $I_{\text {tail }}$. However, protein kinase $G$ inhibition had no effect. Therefore, these results indicate that a component of $I_{\text {tail }}$ is attributable to activation of CNG channels. We conclude that $\mathrm{Ca}^{2+}$ influx when combined with muscarinic receptor activation activates soluble guanylate cyclase and increases cGMP levels. The increased cGMP activates CNG channels and leads to prolonged depolarization. The cation conductance of the CNG channel contributes to the prolonged depolarization of the plateau potential.

Key words: seizure; acetylcholine; muscarinic receptors; cGMP; guanylate cyclase; hippocampus; epilepsy
We first reported that $\mathrm{Ca}^{2+}$ influx in combination with muscarinic $(\mathrm{m} 1 / \mathrm{m} 3)$ or metabotropic glutamate receptor (mGluR) stimulation generates prolonged depolarizations called plateau potentials (PP) in hippocampal pyramidal neurons (Fraser and MacVicar, 1996). We hypothesized that the PP was generated by a Ca ${ }^{2+}$-activated cation conductance (Crepel et al., 1994; Congar et al., 1997) because chelating intracellular $\mathrm{Ca}^{2+}$ prevented the $\mathrm{Na}^{+}$-mediated depolarization. Other reports have shown that plateau potentials occur in pyramidal neurons of other cortical regions (Klink and Alonso, 1997; Kawasaki et al., 1999). The PP is an attractive candidate for a major intrinsic conductance generating the prolonged depolarization observed during ictal phase of seizures (Dichter and Ayala, 1987; Fraser and MacVicar, 1996). Indirectly supporting this postulate is the observation that the PP is depressed by anticonvulsants, such as topiramate (Palmieri et al., 2000). However, the identity of the cation conductance generating the PP is still unknown.

We have investigated the contribution of cyclic nucleotidegated $(\mathrm{CNG})$ channels to the depolarizing current during the plateau potential. $\mathrm{CNG}$ channels are nonselective cation channels that in some configurations are also permeated by $\mathrm{Ca}^{2+}$ (Zagotta

Received May 10, 2001; revised Aug. 2, 2001; accepted May 31, 2001.

This work was supported by grants from Canadian Institutes of Health Research (CIHR). J.B.K. was supported by a studentship from the Savoy Foundation, and B.A.M. held Senior Scientist awards from CIHR and Alberta Heritage Foundation for Medical Research. We thank Dr. P. Schnetkamp for helpful comments.

Correspondence should be addressed to Dr. Brian A. MacVicar, Neuroscience Research Group, Department of Physiology and Biophysics, 3330 Hospital Drive N.W., Faculty of Medicine, University of Calgary, Calgary, Alberta T2N 4N1, Canada. E-mail: macvicar@ucalgary.ca.

Copyright (ㄷ) 2001 Society for Neuroscience $\quad 0270-6474 / 01 / 218707-08 \$ 15.00 / 0$ and Siegelbaum, 1996; Zufall et al., 1997). Several species of CNG channels have been cloned (Finn et al., 1996; Zagotta and Siegelbaum, 1996), and the olfactory CNG is expressed in the hippocampus (el-Husseini et al., 1995; Kingston et al., 1996; Bradley et al., 1997; Wei et al., 1998). The CNG channel is most highly expressed in the soma and proximal dendrites of pyramidal cells (Bradley et al., 1997). Cultured hippocampal neurons exhibit a cation current that is activated by a cGMP analog (Kingston et al., 1996; Bradley et al., 1997). Some (Kingston et al., 1996), but not all laboratories (Bradley et al., 1997) have reported the expression of the rod CNG channel in the hippocampus. The CNG channel is a potential candidate for the depolarizing current underlying the PP because cGMP metabolism is increased by muscarinic receptor or mGluR activation (Trivedi and Kramer, 1998; Wotta et al., 1998). Also, $\mathrm{Ca}^{2+}$ influx could potentially activate guanylate cyclase (GC) by stimulating formation of nitric oxide (NO) (Kingston et al., 1999).

Our strategy to delineate the roles for $\mathrm{CNG}$ channels in the PP required the use of whole-cell voltage clamping to quantify the tail current $\left(I_{\text {tail }}\right)$ underlying the PP. We first ensured that we could voltage clamp the tail current, and then we examined the sensitivity of the current to pharmacological antagonists to the CNG channel. We report that blocking soluble GC (sGC) with 6-anilino-5,8-quinolinequinone (LY83583) (Leinders-Zufall and Zufall, 1995) or 1H-[1,2,4]oxadiazolo[4,3-a]quinoxalin-1-one (ODQ) (Garthwaite et al., 1995) depressed the generation of $I_{\text {tail }}$. Antagonists to the $\mathrm{CNG}$ channel itself $\left(2^{\prime}, 4^{\prime}\right.$-dichlorobenzamil or L-cis-diltiazem) (Zagotta and Siegelbaum, 1996; Wei et al., 1998) also reversibly inhibited $I_{\text {tail }}$; however, blocking the protein kinase activated by cGMP [protein kinase $\mathrm{G}(\mathrm{PKG})$ ] and antagonists to 
NO synthase (NOS) had no effect on $I_{\text {tail }}$. Therefore, we conclude that $\mathrm{Ca}^{2+}$ influx in combination with muscarinic stimulation leads to cGMP formation that depolarizes pyramidal neurons by opening CNG channels.

\section{MATERIALS AND METHODS}

Hippocampal slice preparation. Hippocampal slices were prepared from Sprague Dawley rats, aged postnatal days 15-23. A block of tissue containing the hippocampus and surrounding structures was attached to a mounting tray with cyanoacrylate glue and immersed in chilled $\left(0-4^{\circ} \mathrm{C}\right)$ modified oxygenated $\left(95 \% \mathrm{O}_{2}\right.$ and $\left.5 \% \quad \mathrm{CO}_{2}\right)$ artificial CSF (aCSF) containing (in mM): $120 \mathrm{NaCl}, 3.0 \mathrm{KCl}, 1.3 \mathrm{MgSO}_{4}, 2.0 \mathrm{CaCl}_{2}, 1.5$ $\mathrm{KH}_{2} \mathrm{PO}_{4}, 26 \mathrm{NaHCO}_{3}$, and $10 \mathrm{D}$-glucose, $\mathrm{pH}$ 7.35. Horizontal slices (400 $\mu \mathrm{m}$ ) were cut through the tissue block using a vibratome (VT100; Leica, Willowdale, Ontario, Canada). The slices were then transferred to a storage chamber with oxygenated aCSF and allowed to recover for at least $1 \mathrm{hr}$ at room temperature.

Electrophysiology. Whole-cell voltage-clamp recordings (Hamill et al., 1981) from CA1 neurons within hippocampal slices were obtained using the "blind-patch" technique (Blanton et al., 1989). Slices were individually transferred to a recording chamber located on an upright microscope (Axioskop; Zeiss, Oberkochen, Germany) and submerged in rapidly flowing $(1 \mathrm{ml} / \mathrm{min})$ oxygenated aCSF. Bath temperature was maintained at $32-34^{\circ} \mathrm{C}$ with a Peltier unit and Cambion bipolar controller. The recording electrodes were pulled from $1.5 \mathrm{~mm}$ (outer diameter) borosilicate thin-walled glass capillaries (150F-4; World Precision Instruments, Sarasota, FL) in three stages on a Flaming-Brown micropipette puller (model P-87; Sutter Instruments, Novato, CA). Patch electrodes were filled with a solution containing (in mM): 115 Cs-methanesulphonate, 20 $\mathrm{KCl}, 10$ Na-phosphocreatine, 10 HEPES, and 1.1 EGTA, pH 7.25. In some experiments, $10 \mathrm{~mm}$ BAPTA was substituted for the EGTA as described. When filled with intracellular solution, patch electrode resistance ranged from 4 to $8 \mathrm{M} \Omega$. All experiments were conducted in extracellular solution containing tetrodotoxin (TTX) $(1.2 \mu \mathrm{M})$.

Membrane potentials and/or currents were monitored with either an Axoclamp 2A or Axopatch 200B amplifier (Axon Instruments, Foster City, CA), acquired through a Digidata 1200 series analog-to-digital interface onto a Pentium personal computer using Clampex 7.0 software (Axon Instruments). Data were sampled at a rate of $2-5 \mathrm{kHz}$ and were low-pass filtered (four-pole Bessel) at $1-5 \mathrm{kHz}$. Series resistance was continuously monitored with hyperpolarizing voltage steps. Recordings with series resistance $>20 \mathrm{M} \Omega$ were rejected from analysis.

All chemicals were purchased from Sigma (St. Louis, MO), Molecular Probes (Eugene, OR), or Calbiochem (La Jolla, CA). Carbachol (Sigma), tetrodotoxin (Sigma), L-cis-diltiazem (Sigma), N ${ }^{\mathrm{G}}$-nitro-L-arginine (L-NNA) (Sigma), and $\mathrm{N}^{\mathrm{G}}$-nitro-L-arginine methyl ester, $\mathrm{HCl}$ (LNAME) (Calbiochem) were dissolved in distilled $\mathrm{H}_{2} \mathrm{O}$ and added to the aCSF from concentrated stocks. ODQ (Sigma), LY83583 (Sigma), 2', 4' dichlorobenzamil, $\mathrm{HCl}$ (Molecular Probes), and zaprinast (Calbiochem) were first made up as a stock in DMSO before being added to the aCSF. The final concentration of DMSO was always $\leq 0.1 \%$; in control experiments, DMSO at these concentrations did not alter $I_{\text {tail }}$. BAPTA, tetracesium salt (Molecular Probes), KT5823 (Calbiochem), L-NNA, and L-NAME were dissolved directly into the patch-pipette solution.

Data analysis. Data were analyzed using Clampfit 8.0 (Axon Instruments). $I_{\text {tail }}$ was quantified in each cell by calculating the area under the tail current. Area was calculated by summing the amplitudes of all individual data samples over time, relative to the baseline of prestimulus holding current. Samples were summed from the end of the depolarizing voltage command pulse over a $13 \mathrm{sec}$ time period or to the point at which the current amplitude returned to prestimulus levels. Statistical comparisons were determined using either Student's $t$ test or one-way ANOVA with Tukey's post hoc test (SPSS version 10.0; SPSS, Chicago, IL). In all cases, $p<0.05$ was considered significant. Values are reported as mean \pm SEM.

\section{RESULTS}

The results in this paper were obtained from 134 CA1 pyramidal neurons in the hippocampal slice preparation, using whole-cell patch-clamp techniques. Whole-cell recordings were made with patch pipettes containing a $\mathrm{Cs}^{+}$-based internal solution to reduce $\mathrm{K}^{+}$currents and to improve space clamp (Colino and Halliwell, 1993). All experiments were performed in the presence of bath-

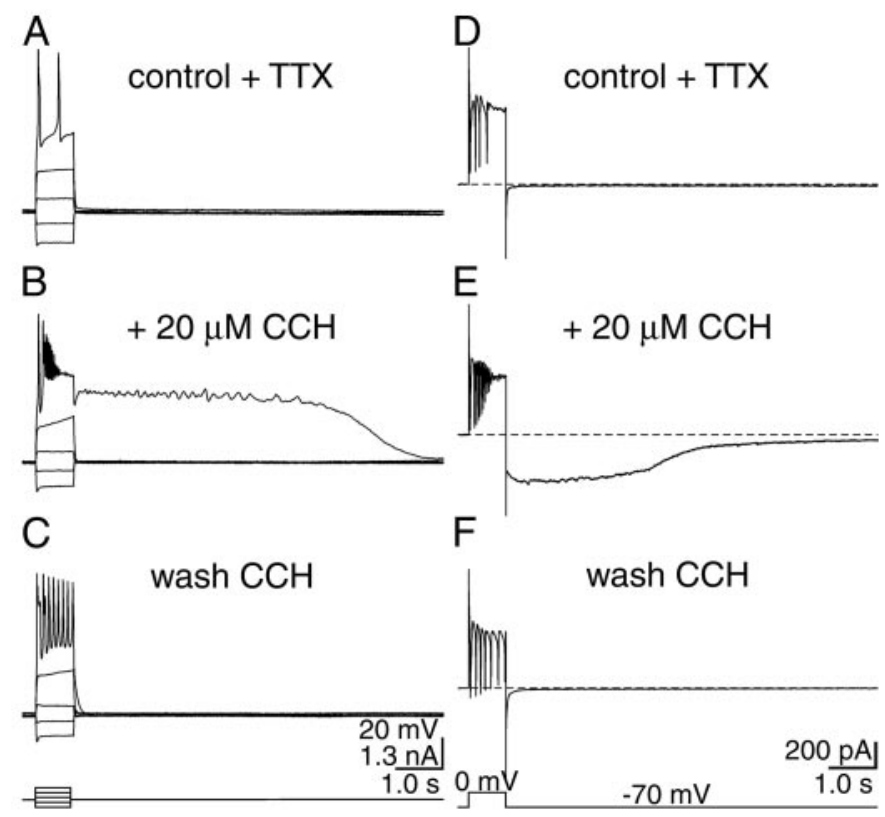

Figure 1. In the presence of carbachol, an $I_{\text {tail }}$ was observed under voltage clamp in the same cells that revealed a PP in current-clamp mode. $A$, Typical responses of a hippocampal CA1 pyramidal neuron under current-clamp conditions to hyperpolarizing and depolarizing current injection in control aCSF. Depolarizing current injection elicited robust $\mathrm{Ca}^{2+}$ spikes, and the membrane potential immediately returned to baseline levels after cessation of the current pulse. $B$, In the presence of $20 \mu \mathrm{M}$ carbachol $(C C H), \mathrm{Ca}^{2+}$ spike firing evoked by identical stimuli resulted in a long-lasting PP. $C$, The PP was reversible after carbachol was washed from the slice. $D$, In the same cell, under voltage-clamp conditions in the absence of carbachol, an $800 \mathrm{msec}$ depolarizing voltage pulse to $0 \mathrm{mV}$ from a holding potential of $-70 \mathrm{mV}$ resulted in unclamped $\mathrm{Ca}^{2+}$ currents. At the offset of the pulse, $I_{\text {tail }}$ was not observed. $E$, In the presence of carbachol, a long-lasting inward $I_{\text {tail }}$ was induced at the offset of the depolarizing voltage pulse under voltage-clamp conditions. $F, I_{\text {tail }}$ was reversible after wash of carbachol. Recordings were made with a $\mathrm{Cs}^{+}$based intracellular solution and $1.2 \mu \mathrm{M}$ TTX in the external solution.

applied TTX $(1.2 \mu \mathrm{M})$ to block voltage-gated $\mathrm{Na}^{+}$channels and to prevent $\mathrm{Na}^{+}$-dependent action potentials.

\section{Cholinergic-dependent plateau potential and slow inward tail current}

In the absence of carbachol, a nonhydrolyzable cholinergic agonist, positive current injection ( $800 \mathrm{msec}, \geq 0.1 \mathrm{nA})$ resulted in activation of $\mathrm{Ca}^{2+}$-dependent action potentials $(n=15)$ (Fig. $1 A$ ). After cessation of current injection, the membrane potential rapidly returned to resting levels. As shown previously with current-clamp recordings (Fraser and MacVicar, 1996), after a 5 min bath application of $20 \mu \mathrm{M}$ carbachol, current injection evoked $\mathrm{Ca}^{2+}$ spikes that now elicited prolonged PPs (Fig. 1B). The average duration of the PP was $10.3 \pm 1.2 \mathrm{sec}$ (range of 3.7-18.4; $n=$ 15). The PPs produced by carbachol were reversible (Fig. 1C).

Long-lasting $I_{\text {tail }}$ s were observed under voltage clamp in the same pyramidal neurons, which had displayed a PP in carbachol under current-clamp conditions $(n=15 / 15)$ (Fig. 1$)$. We examined $I_{\text {tail }} \mathrm{s}$ at a holding potential of $-70 \mathrm{mV}$ after a voltage step to $0 \mathrm{mV}$ for $800 \mathrm{msec}$ before and after carbachol application. The inward $I_{\text {tail }}$ was observed in a total of 77 pyramidal cells only after $20 \mu \mathrm{M}$ carbachol was applied. Tail currents were quantified by measuring the area of the inward current over a $13 \mathrm{sec}$ time period after the end of the voltage command pulse as described in Materials and Methods. Significant increases in $I_{\text {tail }}$ areas were 
A

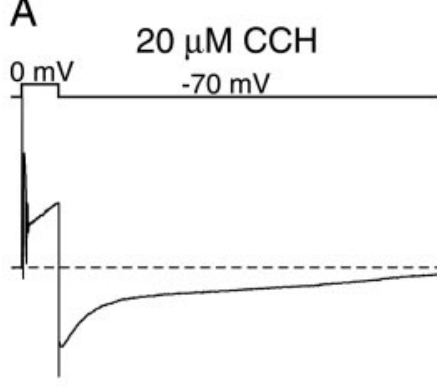

E

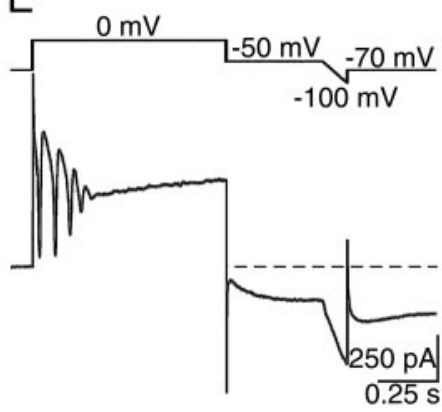

B

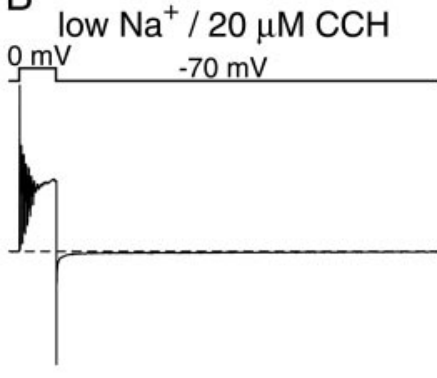

$\mathrm{F}$
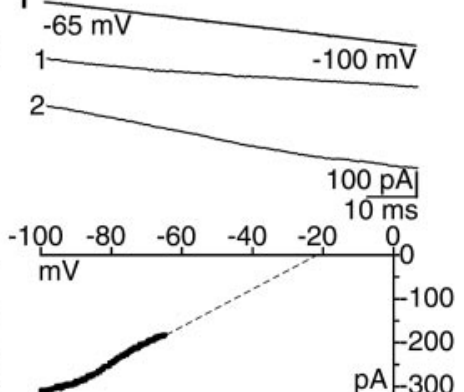

C

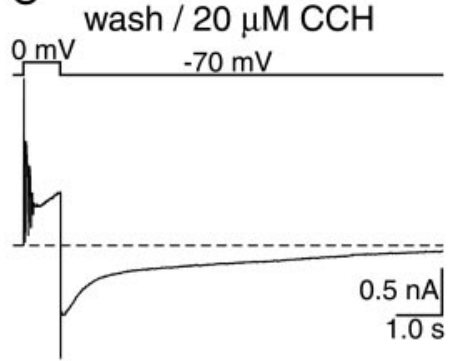

G

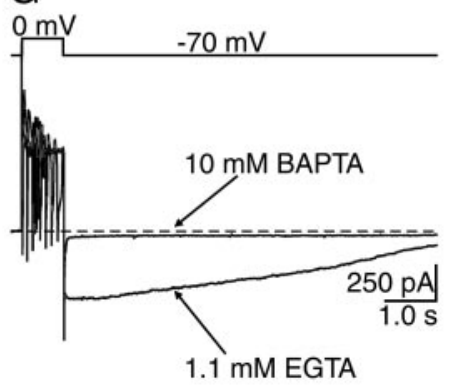

D

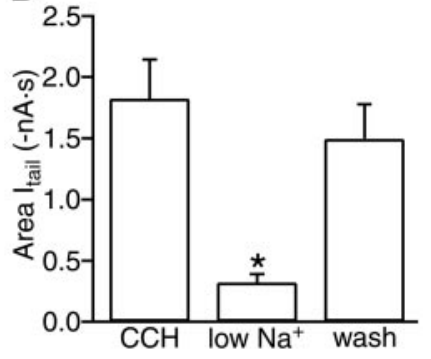

$\mathrm{H}$

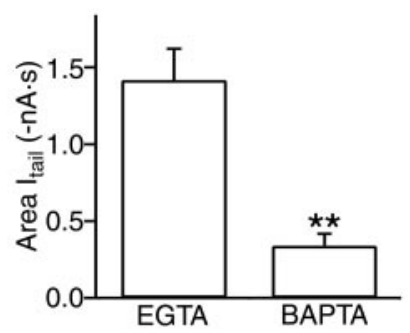

Figure 2. $I_{\text {tail }}$ was dependent on $\mathrm{Na}^{+}$influx independent of TTX-sensitive channels, varied linearly with voltage, and was blocked by intracellular BAPTA. $A$, In $20 \mu \mathrm{M}$ carbachol, $I_{\text {tail }}$ was observed after a depolarizing voltage step $(800 \mathrm{msec})$ to $0 \mathrm{mV}$ from a holding potential of $-70 \mathrm{mV}$. $B$, Reducing $\left[\mathrm{Na}^{+}\right]_{\mathrm{o}}$ from 152 to $26 \mathrm{~mm}$ depressed $I_{\text {tail }}$. External $\mathrm{NaCl}$ was substituted with equimolar $N$-methyl-D-glucamine. $C$, Restoring external $\mathrm{NaCl}$ to $152 \mathrm{mM}$ completely reversed the depression of $I_{\text {tail }}$ induced by low $\left[\mathrm{Na}^{+}\right]_{\mathrm{o}} . D$, Summary of the effects of reducing [Na $\left.{ }^{+}\right]_{\mathrm{o}}$ and after washout on the area of $I_{\text {tail }}$. Mean \pm SE areas of $I_{\text {tail }}$ are plotted $(n=6)$. * $p<0.002$ compared with control data. $E$, The reversal potential of $I_{\text {tail }}$ was assessed by ramping the voltage from -50 to $-100 \mathrm{mV}$ in $100 \mathrm{msec}$ in the presence of carbachol. Ramps obtained during $I_{\text {tail }}$ were compared with ramps obtained from identical voltages without an evoked $I_{\text {tail }} . F$, Subtraction of the ramp currents without $I_{\text {tail }}$ (ramp 1) from the ramp currents during $I_{\text {tail }}$ (ramp 2) from -65 to -100 mV revealed that $I_{\text {tail }}$ varied linearly with membrane potential in the voltage range tested. The reversal potential in this cell determined by linear extrapolation (dotted line) was $-20.1 \mathrm{mV}$. G, Superimposed recordings in carbachol from different CA1 pyramidal neurons from the same slice loaded with intracellular pipette solution containing either $1.1 \mathrm{~mm}$ EGTA or $10 \mathrm{mM}$ BAPTA (indicated by arrows). Chelating $\left[\mathrm{Ca}^{2+}\right]_{\mathrm{i}}$ with BAPTA depressed $I_{\text {tail }} . H$, Summary of the mean $\pm \mathrm{SE} I_{\text {tail }}$ areas from pyramidal neurons recorded with either (in the micropipette) 1.1 mM EGTA $(n=10)$ or 10 mM BAPTA $(n=9)$. $* *<$ 0.001 , EGTA compared with BAPTA.

induced by carbachol (control area, $-0.04 \pm 0.02 \mathrm{nA} \cdot \mathrm{sec}$ vs carbachol, $-1.2 \pm 0.2 \mathrm{nA} \cdot \mathrm{sec} ; p<0.001 ; n=15)($ Fig. $1 D, E)$ when carbachol was washed, $I_{\text {tail }}$ diminished to control levels $(-0.1 \pm 0.02 \mathrm{nA} \cdot \sec ; p<0.001 ; n=15)$ (Fig. $1 F)$.

\section{Reversal potential and sodium dependence of $\boldsymbol{I}_{\text {tail }}$}

Previously, we reported that activation of PPs depends on increased intracellular $\left[\mathrm{Ca}^{2+}\right]\left(\left[\mathrm{Ca}^{2+}\right]_{\mathrm{i}}\right)$ and that the depolarization is attributable to TTX-insensitive $\mathrm{Na}^{+}$influx through a nonselective cation channel (Fraser and MacVicar, 1996). We investigated the role for TTX-insensitive $\mathrm{Na}^{+}$influx in $I_{\text {tail }}$ by replacing extracellular $\left[\mathrm{Na}^{+}\right]\left(\left[\mathrm{Na}^{+}\right]_{\mathrm{o}}\right)$ with equimolar $N$-methylD-glucamine. Reducing $\left[\mathrm{Na}^{+}\right]_{\mathrm{o}}$ from 152 to $26 \mathrm{~mm}$ significantly reduced the area of $I_{\text {tail }}$ (normal aCSF, $-1.8 \pm 0.3 \mathrm{nA} \cdot \mathrm{sec}$ vs low sodium, $-0.3 \pm 0.1 \mathrm{nA} \cdot \mathrm{sec} ; \mathrm{p}<0.002 ; n=6)($ Fig. $2 A, B) ; I_{\text {tail }}$ recovered after replacement of the $\mathrm{NaCl}(-1.5 \pm 0.3 \mathrm{nA} \cdot \mathrm{sec}$ compared with control; $p=0.63 ; n=6$ ) (Fig. $2 C$ ). The results of these experiments are summarized in the plot of $I_{\text {tail }}$ areas in Figure $2 D$.

We next examined the reversal potential for $I_{\text {tail }}$ to see whether a nonselective cation channel underlies the depolarization. A current attributable to a nonselective cation channel should reverse at approximately -20 to $0 \mathrm{mV}$. The $I-V$ relationship of $I_{\text {tail }}$ was obtained by ramping the holding potential from -50 to 100 $\mathrm{mV}$ (in $100 \mathrm{msec}$ ) when $I_{\text {tail }}$ was evoked after a $800 \mathrm{msec}$ depolarizing prepulse to $0 \mathrm{mV}$ in the presence of carbachol $(20 \mu \mathrm{M})$ (protocol shown in Fig. $2 E$ ). Ramp currents obtained during the
$I_{\text {tail }}$ (Fig. 2F2) were compared with ramp currents obtained from identical holding potentials without a prepulse to evoke $I_{\text {tail }}$ (Fig. $2 F 1)$. An example $I-V$ plot is shown in Figure $2 F$. Subtraction of the control ramp current from the ramp current during the $I_{\text {tail }}$ revealed an inward current that showed an extrapolated reversal potential in this cell of approximately $-20 \mathrm{mV}$ (Fig. $2 F$ ). The inward currents revealed by the ramp subtractions were fitted by a computed linear regression $\left(r^{2}=0.98-1\right)$, which were then used to extrapolate the reversal potential. The average reversal potential estimated by linear extrapolation was $-23.6 \pm 8.5 \mathrm{mV}(n=7)$.

\section{$\mathrm{Ca}^{2+}$ dependence of $I_{\text {tail }}$}

In the previous report, PPs were abolished after intracellular perfusion with $10 \mathrm{~mm}$ BAPTA, a $\mathrm{Ca}^{2+}$ chelator (Fraser and MacVicar, 1996). In this study, when we included 10 mM BAPTA in the intracellular solution to prevent $\mathrm{Ca}^{2+}$ increases, the amplitude of $I_{\text {tail }}$ (in the presence of $20 \mu \mathrm{M}$ carbachol) was greatly depressed (Fig. 2G,H). The mean area of $I_{\text {tail }}$ after 15-20 min intracellular perfusion with BAPTA was $-0.3 \pm 0.08 \mathrm{nA} \cdot \mathrm{sec}$ $(\mathrm{n}=9)$. As a control, we recorded $I_{\text {tail }}$ in other cells in the same slices using pipettes filled with control intracellular solution that contained $1.1 \mathrm{~mm}$ EGTA. In the control cells, $I_{\text {tail }}$ was evoked in pyramidal neurons in carbachol, and the area of $I_{\text {tail }}$ was significantly increased compared with BAPTA-filled cells $(-1.4 \pm 0.2$ $\mathrm{nA} \cdot \mathrm{sec} ; n=10 ; \mathrm{p}<0.001)$. These data suggest that, similar to the PP, activation of $I_{\text {tail }}$ is dependent on elevations in $\left[\mathrm{Ca}^{2+}\right]_{\mathrm{i}}$. 

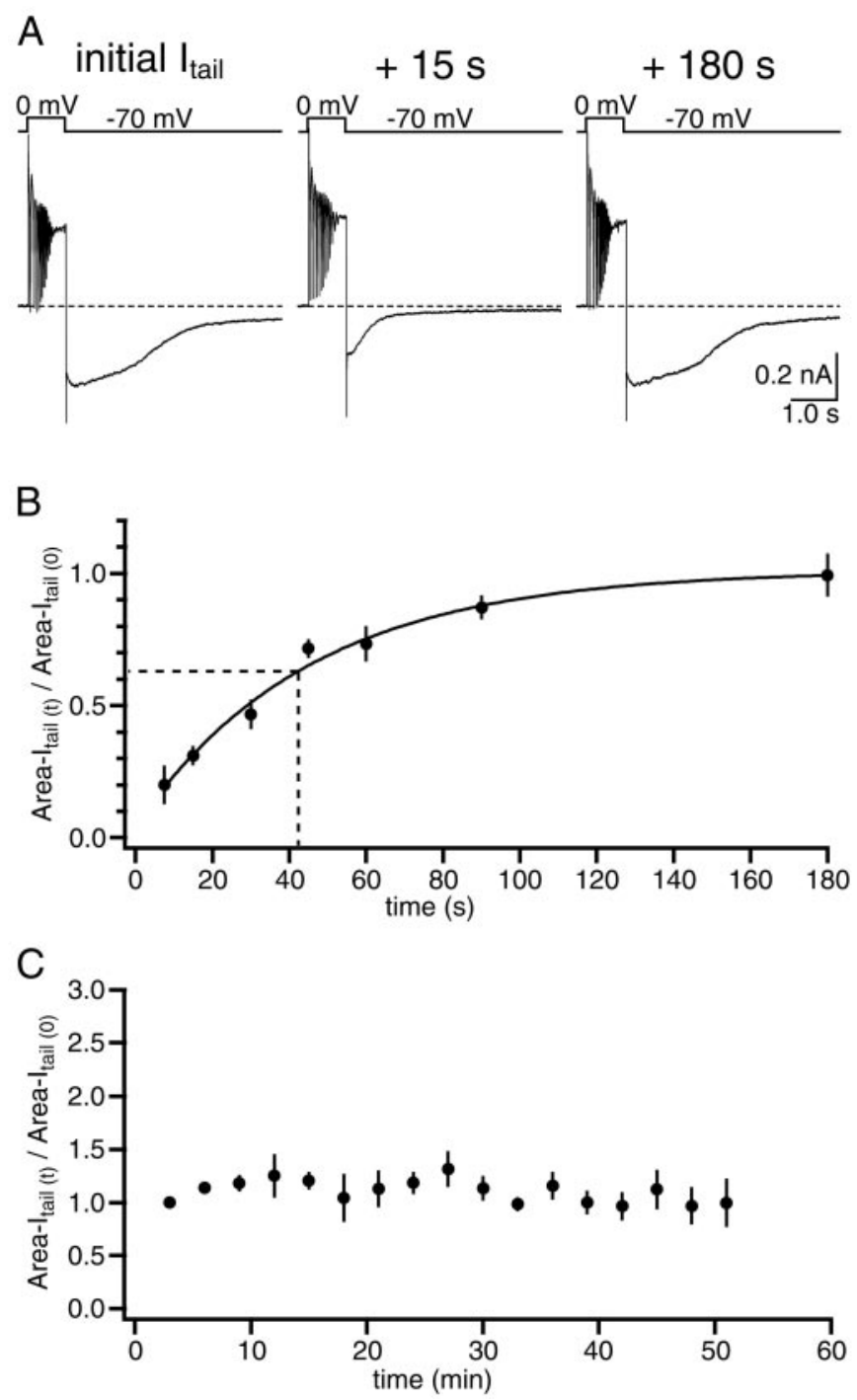

Figure 3. $I_{\text {tail }}$ was refractory when evoked at short intervals but was stable for up to $1 \mathrm{hr}$ when evoked at $>3$ min intervals. $A, I_{\text {tail }}$ was evoked in the presence of $20 \mu \mathrm{M}$ carbachol with a depolarizing voltage step to $0 \mathrm{mV}$ from a holding potential of $-70 \mathrm{mV}(l e f t)$. Another depolarizing voltage step to $0 \mathrm{mV} 15 \mathrm{sec}$ after the initial $I_{\text {tail }}$ was evoked resulted in an $I_{\text {tail }}$ with a reduced area (middle). A depolarizing voltage step to $0 \mathrm{mV} 180 \mathrm{sec}$ after an initial $I_{\text {tail }}$ was evoked resulted in a $I_{\text {tail }}$ with a similar area $(r i g h t) . B$, Plot of the normalized mean $\pm \mathrm{SE} I_{\text {tail }}$ areas at intervals of 7.5, 15, 30, 45, 60,90 , and $180 \mathrm{sec}$ with respect to the initial evoked $I_{\text {tail }}$, showing that activation of $I_{\text {tail }}$ had a refractory period $(n=9)$. A single exponential curve was fit (solid line), and the time constant of recovery was calculated to be $43.5 \mathrm{sec}$ (indicated by dotted lines). $C$, The normalized mean $\pm \mathrm{SE} I_{\text {tail }}$ areas evoked every $3 \mathrm{~min}$ were plotted against time for $51 \mathrm{~min}(n=6)$.

\section{$I_{\text {tail }}$ is refractory}

Before we could examine the actions of pharmacological agents on $I_{\text {tail }}$, we had to ensure that $I_{\text {tail }}$ could be reliably evoked at a specific intervals and that it was stable over extended periods of time. We found that, if $I_{\text {tail }}$ was evoked with intervals $<3 \mathrm{~min}$, the area of the current was significantly reduced (Fig. $3 A$ ). The normalized area of $I_{\text {tail }}$ recorded at various intervals is plotted in Figure $3 B$, showing the gradual recovery with longer intervals. A single exponential curve was fit to the normalized current areas at intervals of $7.5,15,30,45,60,90$, and $180 \mathrm{sec}$ after an initial $I_{\text {tail }}$ was evoked. The time constant of recovery of $I_{\text {tail }}$ to $63 \%$ was 43.5 $\sec (n=9)$, calculated from the fit curve. $I_{\text {tail }}$ was fully recovered at $180 \mathrm{sec}$. To examine rundown over an extended time, $I_{\text {tail }}$ was activated every $180 \mathrm{sec}$ for up to $1 \mathrm{hr}$ (Fig. 3C). After $51 \mathrm{~min}$, the area of the $I_{\text {tail }}$ was $99.8 \pm 22.9 \%$ of the first $I_{\text {tail }}$ evoked $(n=6)$ (Fig. $3 C$ ). Plateau potentials in subiculum have also been shown to be refractory when elicited in short intervals (Kawasaki et al., 1999).

\section{$I_{\text {tail }}$ requires activation of guanylate cyclase independent of PKG activity}

To explore the possibility that carbachol and/or $\mathrm{Ca}^{2+}$ act via a cGMP-dependent pathway (Trivedi and Kramer, 1998; Wotta et al., 1998), we tested inhibitors of steps in cGMP signaling. First, we evaluated the effects of inhibitors of sGC. LY83583 $(20 \mu \mathrm{M})$, an inhibitor of guanylate cyclase and cGMP channels, reduced the area of $I_{\text {tail }}$ (control, $-1.7 \pm 0.4 \mathrm{nA} \cdot \mathrm{sec}$ vs LY83583, $-0.3 \pm$ $0.07 \mathrm{nA} \cdot \sec ; p<0.02 ; n=5$ ) (Fig. $4 A, B$ ). In several neurons, the later portion of $I_{\text {tail }}$ was blocked in contrast to the complete lack of residual $I_{\text {tail }}$ when BAPTA was included in the pipette or $\left[\mathrm{Na}^{+}\right]_{\mathrm{o}}$ was reduced (Fig. 2). ODQ $(20 \mu \mathrm{M})$, another sGC inhibitor with no reported action on the cGMP channel (Garthwaite et al., 1995), inhibited the activation of $I_{\text {tail }}$ (area in ODQ, $-0.5 \pm$ $0.1 \mathrm{nA} \cdot \mathrm{sec}$ compared with area of control, $-1.5 \pm 0.2 \mathrm{nA} \cdot \mathrm{sec}$; $p<0.02 ; n=5)$. The results of the experiments with the guanylate cyclase inhibitors are summarized in Figure $4 C$. Conversely, we examined the effects of inhibiting cGMP-specific phosphodiesterase by bath application of zaprinast $(20 \mu \mathrm{M})$ to see whether the area of $I_{\text {tail }}$ was enhanced when cGMP levels were potentially increased. We used a submaximal concentration of carbachol $(5 \mu \mathrm{M})$ to elicit $I_{\text {tail }}$. To quantify the actions of zaprinast, we first evoked $I_{\text {tail }}$ twice in control solution, and then zaprinast was bath applied for $>8 \mathrm{~min}$ and $I_{\text {tail }}$ was again evoked. All values for $I_{\text {tail }}$, including the washout values, were normalized to the first control. The normalized area of the $I_{\text {tail }}$ increased from $1.1 \pm 0.1$ in control to $2.4 \pm 0.6$ in zaprinast $(n=10 ; p<0.05)$. The enhancement of $I_{\text {tail }}$ was reversible as the area decreased to $1.5 \pm 0.3$ (not significantly different compared with control) when zaprinast was washed out. In the example shown in Figure $4 D-F$, bath application of zaprinast reversibly enhanced the area of $I_{\text {tail }}$. These results indicate that $I_{\text {tail }}$ was dependent on increased cGMP levels that could elicit $I_{\text {tail }}$ by either activating CNG channels directly in CA1 pyramidal neurons or by activating cGMP-dependent protein kinases (PKG).

Although we found previously that activation of protein kinases and phosphorylation was unnecessary for PP genesis (Fraser et al., 2001), we determined the involvement of PKG, which can be activated by cGMP. Intracellular perfusion of the selective PKG inhibitor KT5823 (10 $\mu \mathrm{M})$ (Lei et al., 2000) in the patch pipette for $30 \mathrm{~min}$ failed to inhibit $I_{\text {tail }}$ (Fig. $4 C$ ). In the same slices in which control intracellular solution was used, there was not a significant difference in the area of $I_{\text {tail }}$ (control, $-1.8 \pm 0.2$ $\mathrm{nA} \cdot \sec$ vs KT5823, $-1.6 \pm 0.1 \mathrm{nA} \cdot \mathrm{sec} ; p=0.36 ; n=5)$. Therefore, we conclude that a guanylate cyclase-cGMP pathway, independent of PKG, is required for activation of $I_{\text {tail }}$.

\section{$I_{\text {tail }}$ is mediated by cGMP-gated cation channels}

To test the hypothesis that $I_{\text {tail }}$ is mediated by cGMP-gated cation channels, we used bath applications of two CNG channel blockers, 2',4'-dichlorobenzamil and L-cis-diltiazem (Koch and Kaupp, 1985; Nicol et al., 1987). The first CNG channel blocker that we used was the amiloride derivative $2^{\prime}, 4^{\prime}$-dichlorobenzamil (100 $\mu \mathrm{M})$. In the example shown in Figure $5 A-C$, application of $2^{\prime}, 4^{\prime}$ dichlorobenzamil reversibly reduced the area of the $I_{\text {tail }}$. The 

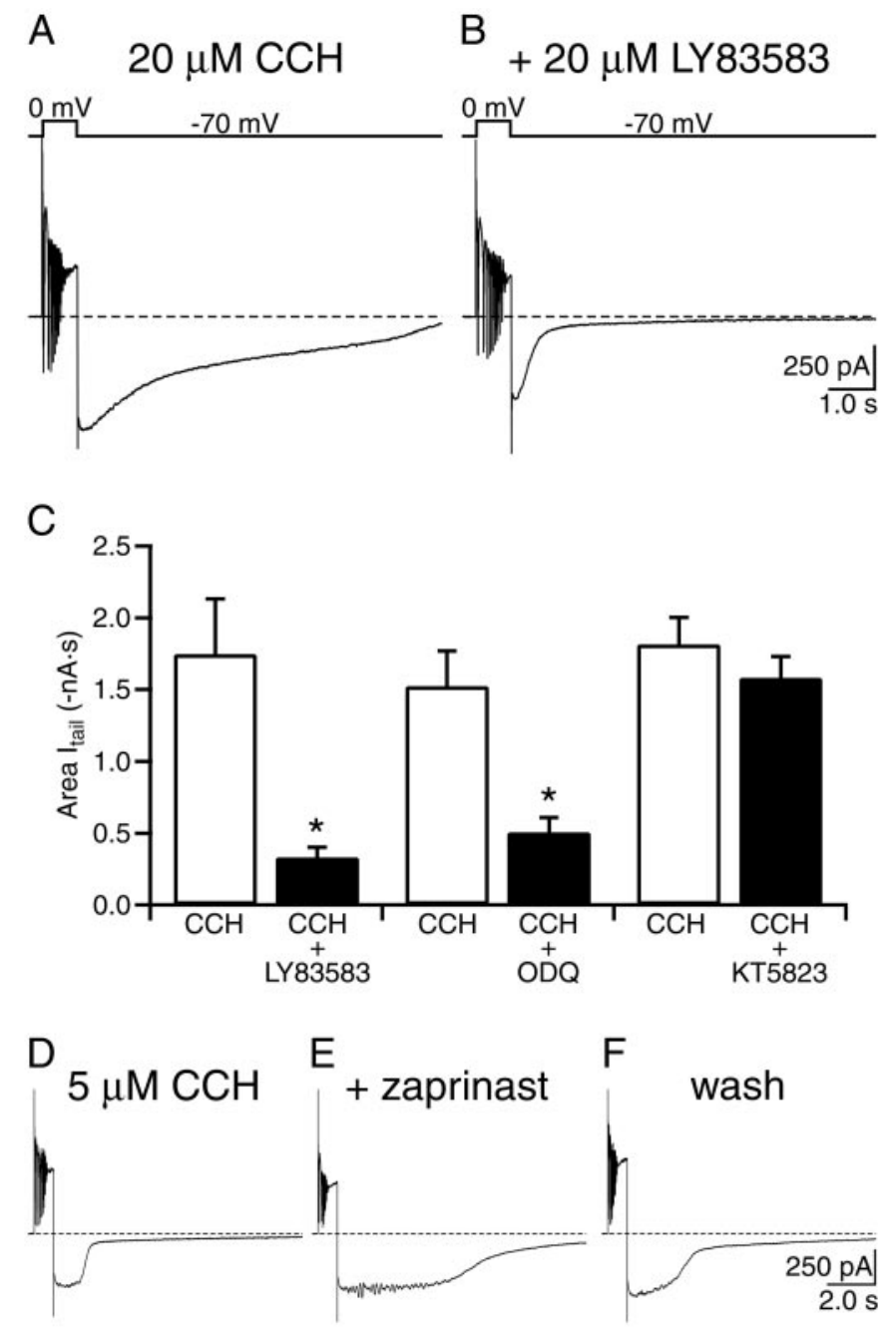

Figure 4. $I_{\text {tail }}$ required sGC activity but was independent of PKG activity. $A$, In the presence of $20 \mu \mathrm{M}$ carbachol $(C C H), I_{\text {tail }}$ could be evoked with a depolarizing voltage step to $0 \mathrm{mV}$ from a holding potential of -70 $\mathrm{mV}$. B, After bath application of $20 \mu \mathrm{M} \mathrm{LY83583,} I_{\text {tail }}$ was depressed. $C$, Summary of the mean \pm SE $I_{\text {tail }}$ areas in the presence of the sGC inhibitors LY83583 or ODQ or a PKG inhibitor compared with $I_{\text {tail }}$ controls. Bath application of either $20 \mu \mathrm{M} \mathrm{LY83583}(n=5)$ or $20 \mu \mathrm{M}$ ODQ $(n=5)$ significantly depressed $I_{\text {tail }}$ area. * $p<0.02$, compared with control $I_{\text {tail }}$ areas. Intracellular perfusion of the PKG inhibitor KT5823 $(10 \mu \mathrm{M})$ for $>30 \mathrm{~min}$ did not alter $I_{\text {tail }}$ area $(n=5$, KT5823; $n=5$, control). $I_{\text {tail }}$ areas from cells perfused with KT5823 were compared with control areas of $I_{\text {tail }}$ obtained from pyramidal neurons in the same slices. $D, I_{\text {tail }} \mathrm{s}$ of reduced areas were evoked with a depolarizing voltage step to $0 \mathrm{mV}$ from a holding potential of $-70 \mathrm{mV}$ with perfusion of a submaximal dose of carbachol $(5 \mu \mathrm{M})$. E, Bath application of zaprinast enhanced the evoked $I_{\text {tail }} . F$, The increase in $I_{\text {tail }}$ area by zaprinast was reversible after wash.

results of these experiments are summarized in the plot of the $I_{\text {tail }}$ area in Figure $5 D$. Significant changes in $I_{\text {tail }}$ area were induced by 2',4'-dichlorobenzamil (control, $-2.1 \pm 0.2 \mathrm{nA} \cdot \sec$ vs $2^{\prime}, 4^{\prime}$ dichlorobenzamil, $-0.3 \pm 0.06 \mathrm{nA} \cdot \sec ; p<0.001 ; n=7)$; this reduction in area of $I_{\text {tail }}$ was reversible $(-1.6 \pm 0.2 \mathrm{nA} \cdot \mathrm{sec} ; p=$ 0.2 compared with control; $n=7$ ).

We also examined the effects of L-cis-diltiazem on the carbachol-activated $I_{\text {tail }}$. L-cis-diltiazem is the inactive isomer of a $\mathrm{Ca}^{2+}$ channel blocker that has been reported to inhibit CNG channels. The site of action of L-cis-diltiazem is suggested to be located on the cytoplasmic side of the channel (Koch and Kaupp,
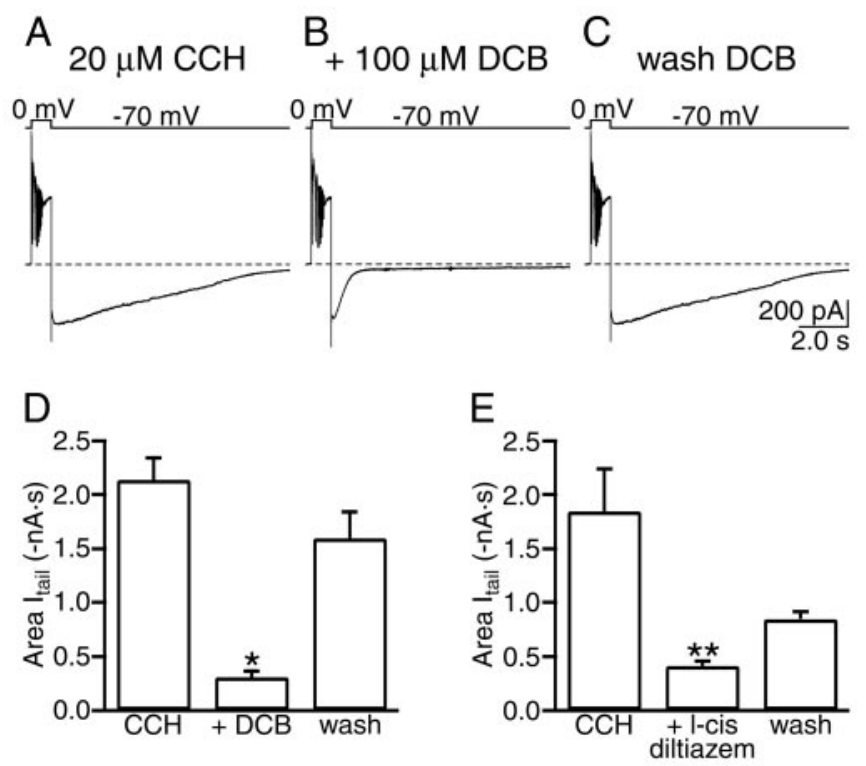

Figure 5. Antagonists of cyclic nucleotide-gated channels depressed $I_{\text {tail }}$. $A$, In the presence of $20 \mu \mathrm{M}$ carbachol $(C C H), I_{\text {tail }}$ was evoked with depolarizing voltage steps to $0 \mathrm{mV}$ from a holding potential of $-70 \mathrm{mV}$. $B$, Bath application of $100 \mu \mathrm{M} 2^{\prime}, 4^{\prime}$-dichlorobenzamil $(D C B)$ depressed generation of $I_{\text {tail }} . C$, The inhibition of $I_{\text {tail }}$ was reversible after wash of $2^{\prime}, 4^{\prime}$-dichlorobenzamil. $D$, Summary plot of the mean \pm SE areas of $I_{\text {tail }}$ before, after, and wash of $2^{\prime}, 4^{\prime}$-dichlorobenzamil. Application of $2^{\prime}, 4^{\prime}$ dichlorobenzamil reversibly depressed $I_{\text {tail }}\left(n=7 ;{ }^{*} p<0.001\right)$ compared with $I_{\text {tail }}$ control. E, Summary of the effects of bath application of L-cisdiltiazem on mean $\pm \mathrm{SE} I_{\text {tail }}$ area. $I_{\text {tail }}$ was depressed by L-cis-diltiazem $\left(n=7 ;{ }^{*} p<0.01\right.$ compared with control). In three neurons that were stable in the wash for $>30 \mathrm{~min}, I_{\text {tail }}$ partially recovered from the depression induced by L-cis-diltiazem.

1985; Stern et al., 1986; Haynes, 1992; McLatchie and Matthews, 1992, 1994). However, at physiological pH, $\sim 50 \%$ of the L-cisdiltiazem is unprotonated and can cross the membrane. Therefore, L-cis-diltiazem was bath applied. Figure $5 E$ shows that L-cisdiltiazem $(100 \mu \mathrm{M})$ inhibited activation of $I_{\text {tail }}$. The area of $I_{\text {tail }}$ was reduced from $-1.8 \pm 0.4 \mathrm{nA} \cdot \mathrm{sec}$ in control to $-0.4 \pm 0.05$ $\mathrm{nA} \cdot \sec$ after application of L-cis-diltiazem $(p<0.01 ; n=7)$. A subset of these cells $(n=3)$ were stable for $>30 \mathrm{~min}$ in wash in carbachol containing aCSF, and $I_{\text {tail }}$ recovered to $-0.9 \pm 0.1$ $\mathrm{nA} \cdot \mathrm{sec}$ in these cells. Similar to the effects of sGC inhibition, there was still a residual $I_{\text {tail }}$ observed in several neurons after inhibition of CNG channels with $2^{\prime}, 4^{\prime}$-dichlorobenzamil (Fig. 5) or L-cis-diltiazem.

\section{Effect of nitric oxide synthase inhibitors on $\boldsymbol{I}_{\text {tail }}$}

We tested the possibility that NO causes the increased guanylate cyclase activity required for activation of $I_{\text {tail }}$ by applying two inhibitors of NOS. Slices were bathed for $>1 \mathrm{hr}$ in aCSF containing the NOS inhibitors L-NAME (1 mM) or L-NNA $(100 \mu \mathrm{M})$. $I_{\text {tail }} \mathrm{S}$ evoked in these slices did not differ from those evoked in control slices [control, $-1.6 \pm 0.5 \mathrm{nA} \cdot \mathrm{sec}$ vs L-NAME, $-1.4 \pm$ $0.3 \mathrm{nA} \cdot \sec (p=1.00 ; n=5)$ or vs L-NNA, $-1.3 \pm 0.2 \mathrm{nA} \cdot \mathrm{sec}$ $(p=0.98 ; n=5)]$. In addition, neither L-NAME (1 mM) (control, $-1.6 \pm 0.5 \mathrm{nA} \cdot \sec$ vs L-NAME, $-1.6 \pm 0.4 \mathrm{nA} \cdot \mathrm{sec} ; p=1.00 ; n=$ 10) nor L-NNA $(500 \mu \mathrm{M})($ control, $-1.6 \pm 0.5 \mathrm{nA} \cdot \mathrm{sec}$ vs L-NNA, $-1.6 \pm 0.3 \mathrm{nA} \cdot \mathrm{sec} ; p=1.00 ; n=10)$ had any significant effect on $I_{\text {tail }}$ when included in the intracellular recording electrode (Fig. 6). 
A

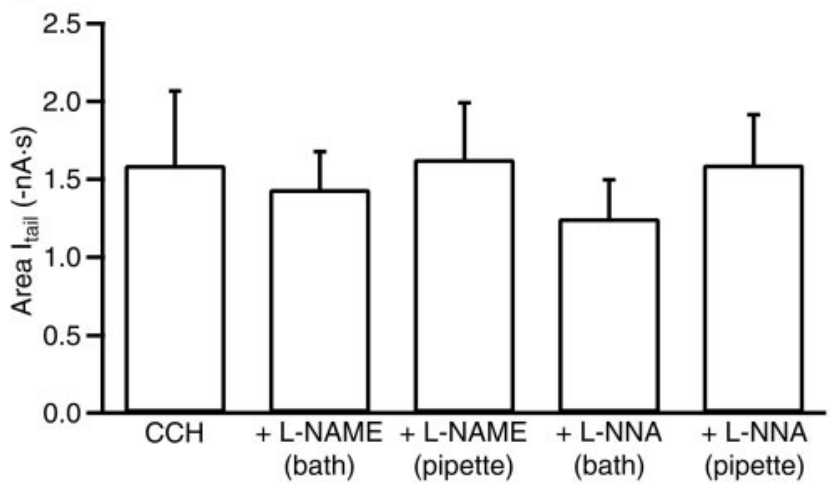

Figure 6. $I_{\text {tail }}$ was independent of nitric oxide production. $A$, The effects of the nitric oxide inhibitors L-NAME and L-NNA are summarized in the histogram. $I_{\text {tail }}$ area was not depressed by either bath application for $>1 \mathrm{hr}$ $(1 \mathrm{mM})(n=5)$ or intracellular perfusion $(1 \mathrm{mM})(n=10)$ of L-NAME. Inhibition of nitric oxide synthase by bath application $(n=5)$ or intracellular perfusion $(n=10)$ of L-NNA did not affect $I_{\text {tail }}$ area.

\section{DISCUSSION}

The results in this paper indicate that $\mathrm{CNG}$ channels contribute to the prolonged depolarization during the cholinergic plateau potential. We used whole-cell voltage-clamp recordings to quantify the $I_{\text {tail }}$ after voltage steps to activate $\mathrm{Ca}^{2+}$ currents in CA1 pyramidal neurons. A significant $I_{\text {tail }}$ was only observed when carbachol was perfused. The reversal of $I_{\text {tail }}$ at $-20 \mathrm{mV}$ indicated that the current was likely attributable a nonselective cation channel. The inward current was carried principally by $\mathrm{Na}^{+}$and was blocked by including high concentrations of the $\mathrm{Ca}^{2+}$ chelator BAPTA in the pipette. The current did not exhibit significant rundown over $1 \mathrm{hr}$ when evoked at intervals of $>3 \mathrm{~min}$. At shorter intervals, $I_{\text {tail }}$ was refractory. Inhibiting sGC with ODQ or LY83835 depressed the current, and, conversely, inhibiting phosphodiesterase, which degrades cGMP, enhanced $I_{\text {tail }}$. Two separate antagonists of the CNG channel, L-cis-diltiazem and $2^{\prime}, 4^{\prime}$ dichlorobenzamil, depressed $I_{\text {tail }}$. Inhibition of the kinase activated by cGMP (PKG) using protocols shown to be effective in other studies (Lei et al., 2000) had no effect. These results indicate that $\mathrm{Ca}^{2+}$ influx activates $\mathrm{sGC}$, leading to increased cGMP levels. The increased cGMP activates CNG channels, causing a depolarization attributable to the nonselective cation conductance. Surprisingly, we could find no evidence that the activation of sGC was attributable to increased NO because high concentrations of NOS inhibitors had no effect on $I_{\text {tail }}$.

CNG channels are a family of related proteins that consist, in the native form, of $\alpha$ subunits, which form homomeric pores, and $\beta$ subunits, which modify channel properties and sensitivity to antagonists when coexpressed with $\alpha$ subunits (Zagotta and Siegelbaum, 1996; Wei et al., 1998; Bonigk et al., 1999). Distinct CNG channels were first described in retinal rod and cone cells and in olfactory cells and are classified as $\mathrm{CNC} \alpha 1$ (rod $\mathrm{CNG}$ channel), $\mathrm{CNC} \alpha 2$ (cone $\mathrm{CNG}$ channel), and $\mathrm{CNC} \alpha 3$ (olfactory CNG channels). There is substantial evidence, however, that CNG channels are more widely expressed and that they play roles in synaptic function in other brain regions, such as the hippocampus (Wei et al., 1998; Kingston et al., 1999). The olfactory CNG channel $(\mathrm{CNC} \alpha 3)$ is expressed in hippocampal pyramidal neurons, and this channel is highly permeable to $\mathrm{Ca}^{2+}$ (el-Husseini et al., 1995; Kingston et al., 1996; Bradley et al., 1997; Wei et al., 1998). The rod CNG channel was found in the hippocampus by

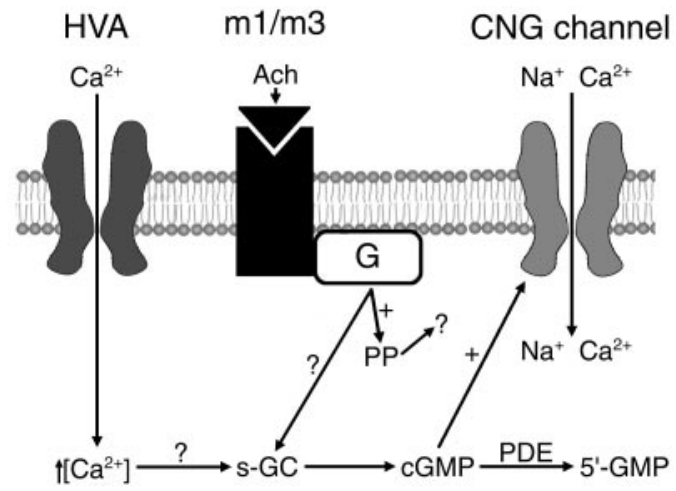

Figure 7. Proposed model for the activation of $I_{\text {tail }}$ and generation of plateau potentials. We propose that stimulation of muscarinic receptors $(m 1 / m 3)$ coupled to G-proteins in combination with $\mathrm{Ca}^{2+}$ influx through high-voltage-activated $\mathrm{Ca}^{2+}$ channels $(H V A)$ can activate sGC, leading to an increase in intracellular cGMP and opening of CNG channels. The mechanism by which $\mathrm{Ca}^{2+}$ activates $\mathrm{sCG}$ does not apparently require nitric oxide. Influx of $\mathrm{Na}^{+}$and $\mathrm{Ca}^{2+}$ through $\mathrm{CNG}$ channel openings mediates $I_{\text {tail }}$ and the prolonged depolarization during the plateau potential. Activation of protein phosphatase $(P P)$ is required for plateau potential generation (Fraser et al., 2001), which may serve to increase the sensitivity of CNG channels to cyclic nucleotides. As part of $I_{\text {tail }}$ termination, cGMP-specific phosphodiesterase $(P D E)$ can metabolize cGMP to $5^{\prime}$-GMP.

some (Kingston et al., 1996) but not all investigators (Bradley et al., 1997). Although application of membrane-permeable forms of cGMP [8-bromo-cGMP (8-Br-cGMP)] induced an inward current in cultured hippocampal neurons (Leinders-Zufall et al., 1995; Bradley et al., 1997), the functions of CNG channels in the hippocampus are unknown. Increased cGMP is apparently involved in the induction of LTP because guanylate cyclase inhibition and Rp-8-Br-cGMPs, a cGMP-dependent protein kinase antagonist, blocked induction of LTP in CA1 (Zhuo et al., 1994; Arancio et al., 1995). In addition, transgenic mice lacking the olfactory CNG $\alpha$ subunit exhibited an attenuation of LTP (Parent et al., 1998).

Our results indicate that activation of $\mathrm{CNG}$ channels contribute to the depolarization during the plateau potential. Our results do not differentiate between olfactory or rod type of CNG channels. There are differences between the two CNG channels that may be used to determine channel type in future experiments. Olfactory CNG channels are blocked by LY83583 (Leinders-Zufall and Zufall, 1995). We observed depression by LY83583; however, LY83583 also inhibits sGC. We also observed inhibition of $I_{\text {tail }}$ by ODQ, another inhibitor of sGC. Therefore, our results do not differentiate between these two possible actions of LY83583, and we cannot attribute the actions of LY83583 to either enzyme inhibition or channel block. This would be best resolved in future experiments by directly activating CNG currents in pyramidal neurons in hippocampal slices by cGMP itself and then testing the effects of LY83583. Inhibition of sGC or antagonists of CNG channels often did not totally block $I_{\text {tail }}$. In contrast, there was no residual $I_{\text {tail }}$ in BAPTA or low $\left[\mathrm{Na}^{+}\right]_{\mathrm{o}}$. It is possible that there are multiple components of $I_{\text {tail }}$ that we have not resolved.

There is substantial $\mathrm{Ca}^{2+}$ permeation of some forms of $\mathrm{CNG}$ channels, particularly the olfactory form (Frings et al., 1995; Leinders-Zufall et al., 1997; Dzeja et al., 1999). The likeliest CNG channel underlying this current in the hippocampus is the olfactory CNG channel (Kingston et al., 1996; Bradley et al., 
1997). This implies that $\mathrm{Ca}^{2+}$ influx will occur in pyramidal cells when $I_{\text {tail }}$ and CNG channels are activated, which could have profound effects on cell signaling. We have confirmed here that the plateau potential is prevented by BAPTA, which will chelate and attenuate rises in $\left[\mathrm{Ca}^{2+}\right]_{\mathrm{i}}$. Therefore, $\mathrm{Ca}^{2+}$ influx through CNG channels would be expected to increase the $\mathrm{Ca}^{2+}$ load in pyramidal neurons, thereby leading to further activation of the plateau potential. The degree of $\mathrm{Ca}^{2+}$ permeability of $\mathrm{CNG}$ channels is also determined by the $\beta$ subunits that are coexpressed with $\alpha$ (Dzeja et al., 1999). If the CNG channel configuration in hippocampal slices (Bradley et al., 1997) is identical to that found in hippocampal cell culture (Kingston et al., 1996), then there should be considerable $\mathrm{Ca}^{2+}$ permeability.

Our results point to several key components in the pathway leading to activation of the CNG channel and the plateau potential, as illustrated in Figure 7. Key steps are the $\mathrm{Ca}^{2+}$ influx leading to increased $\left[\mathrm{Ca}^{2+}\right]_{i}$ and the concurrent activation of muscarinic receptors. We propose that the concurrent stimulation of muscarinic receptors and increased $\left[\mathrm{Ca}^{2+}\right]_{\mathrm{i}}$ leads to activation of sGC and increased cGMP levels. The increased levels of cGMP induces opening of CNG channels, causing the depolarizing current underlying the plateau potential. Both LY83583 and ODQ are potent inhibitors of sGC, and both depressed $I_{\text {tail }}$. The two CNG channel antagonists depressed $I_{\text {tail }}$, consistent with our conclusion that a component of the inward current is attributable to the CNG cation current. The extrapolated reversal potential for $I_{\text {tail }}$ was close to an estimated reversal potential for a mixed cation conductance. We also propose that zaprinast-sensitive phosphodiesterases contribute to the termination of the CNG current because $I_{\text {tail }}$ was enhanced in zaprinast. Protein phosphatase activation also contributes to the generation of the plateau potential (Fraser et al., 2001) in a manner similar to the modulation of $\mathrm{Ca}^{2+}$-activated $\mathrm{K}^{+}$currents by muscarinic receptors (Pedarzani et al., 1998). The transduction pathway between increased $\mathrm{Ca}^{2+}$ and activation of $\mathrm{sGC}$ is still to be determined. When we started these experiments, we hypothesized that $\mathrm{Ca}^{2+}$ dependent activation of NOS could increase NO generation, causing sGC activation (Wotta et al., 1998). Alternatively, muscarinic receptors have been linked to activation of endothelial NOS (Han et al., 1998). However, our results do not support any role for NOS in activation of sGC. Quite high concentrations of two different NOS inhibitors had no effect on $I_{\text {tail }}$. Therefore, the pathway leading to sGC activation is still to be determined. There are alternative explanations for our observations, such as modification of $\left[\mathrm{Ca}^{2+}\right]_{\mathrm{i}}$ mechanisms by cGMP. Conclusive evidence for this model will come from more direct studies in hippocampal neurons on the CNG channel itself.

These findings could be relevant to the generation of seizures and epilepsy. A generalized seizure in the whole animal involves a prolonged depolarization, which is termed the tonic component of the ictal seizure (Dichter and Ayala, 1987). Often this is followed by repetitive depolarizations called the clonic phase. There is no doubt that recurrent collaterals are important in synchronizing neuronal activity in networks leading to seizures (MacVicar and Dudek, 1980; Traub et al., 1989; Jefferys, 1998), and it is likely that multiple currents contribute to seizure generation. However, the conversion of neuronal networks from bursting to prolonged tonic depolarizations could entail the enhancement of a prolonged inward current. The CNG current underlying $I_{\text {tail }}$ is an excellent candidate for an intrinsic current that could be a key contributor to the ictal tonic depolarization.

\section{REFERENCES}

Arancio O, Kandel ER, Hawkins RD (1995) Activity-dependent longterm enhancement of transmitter release by presynaptic $3^{\prime}, 5^{\prime}$-cyclic GMP in cultured hippocampal neurons. Nature 376:74-80.

Blanton MG, Lo Turco JJ, Kriegstein AR (1989) Whole cell recording from neurons in slices of reptilian and mammalian cerebral cortex. J Neurosci Methods 30:203-210.

Bonigk W, Bradley J, Muller F, Sesti F, Boekhoff I, Ronnett GV, Kaupp UB, Frings S (1999) The native rat olfactory cyclic nucleotide-gated channel is composed of three distinct subunits. J Neurosci 19:5332-5347.

Bradley J, Zhang Y, Bakin R, Lester HA, Ronnett GV, Zinn K (1997) Functional expression of the heteromeric "olfactory" cyclic nucleotidegated channel in the hippocampus: a potential effector of synaptic plasticity in brain neurons. J Neurosci 17:1993-2005.

Colino A, Halliwell JV (1993) Carbachol potentiates Q current and activates a calcium-dependent non-specific conductance in rat hippocampus in vitro. Eur J Neurosci 5:1198-1209.

Congar P, Leinekugel X, Ben-Ari Y, Crepel V (1997) A long-lasting calcium-activated nonselective cationic current is generated by synaptic stimulation or exogenous activation of group I metabotropic glutamate receptors in CA1 pyramidal neurons. J Neurosci 17:5366-5379.

Crepel V, Aniksztejn L, Ben-Ari Y, Hammond C (1994) Glutamate metabotropic receptors increase a $\mathrm{Ca}(2+)$-activated nonspecific cationic current in CA1 hippocampal neurons. J Neurophysiol 72:1561-1569.

Dichter MA, Ayala GF (1987) Cellular mechanisms of epilepsy: a status report. Science 237:157-164.

Dzeja C, Hagen V, Kaupp UB, Frings S (1999) $\mathrm{Ca}^{2+}$ permeation in cyclic nucleotide-gated channels. EMBO J 18:131-144.

el-Husseini AE, Bladen C, Vincent SR (1995) Expression of the olfactory cyclic nucleotide gated channel (CNG1) in the rat brain. NeuroReport 6: 1459-1463.

Finn JT, Grunwald ME, Yau KW (1996) Cyclic nucleotide-gated ion channels: an extended family with diverse functions. Annu Rev Physiol 58:395-426.

Fraser DD, MacVicar BA (1996) Cholinergic-dependent plateau potential in hippocampal CA1 pyramidal neurons. J Neurosci 16:4113-4128.

Fraser DD, Doll D, MacVicar BA (2001) Serine/threonine protein phosphatases and synaptic inhibition regulate the expression of cholinergicdependent plateau potentials. J Neurophysiol 85:1197-1205.

Frings S, Seifert R, Godde M, Kaupp UB (1995) Profoundly different calcium permeation and blockage determine the specific function of distinct cyclic nucleotide-gated channels. Neuron 15:169-179.

Garthwaite J, Southam E, Boulton CL, Nielsen EB, Schmidt K, Mayer B (1995) Potent and selective inhibition of nitric oxide-sensitive guanylyl cyclase by $1 \mathrm{H}-[1,2,4]$ oxadiazolo[4,3-a]quinoxalin-1-one. Mol Pharmacol 48:184-188.

Hamill OP, Marty A, Neher E, Sakmann B, Sigworth FJ (1981) Improved patch-clamp techniques for high-resolution current recording from cells and cell-free membrane patches. Pflügers Arch 391:85-100.

Han X, Kubota I, Feron O, Opel DJ, Arstall MA, Zhao YY, Huang P, Fishman MC, Michel T, Kelly RA (1998) Muscarinic cholinergic regulation of cardiac myocyte ICa-L is absent in mice with targeted disruption of endothelial nitric oxide synthase. Proc Natl Acad Sci USA 95:6510-6515.

Haynes LW (1992) Block of the cyclic GMP-gated channel of vertebrate rod and cone photoreceptors by L-cis-diltiazem. J Gen Physiol 100:783-801.

Jefferys JG (1998) Mechanisms and experimental models of seizure generation. Curr Opin Neurol 11:123-127.

Kawasaki H, Palmieri C, Avoli M (1999) Muscarinic receptor activation induces depolarizing plateau potentials in bursting neurons of the rat subiculum. J Neurophysiol 82:2590-2601.

Kingston PA, Zufall F, Barnstable CJ (1996) Rat hippocampal neurons express genes for both rod retinal and olfactory cyclic nucleotide-gated channels: novel targets for cAMP/cGMP function. Proc Natl Acad Sci USA 93:10440-10445.

Kingston PA, Zufall F, Barnstable CJ (1999) Widespread expression of olfactory cyclic nucleotide-gated channel genes in rat brain: implications for neuronal signalling. Synapse 32:1-12.

Klink R, Alonso A (1997) Ionic mechanisms of muscarinic depolarization in entorhinal cortex layer II neurons. J Neurophysiol 77:1829-1843.

Koch KW, Kaupp UB (1985) Cyclic GMP directly regulates a cation conductance in membranes of bovine rods by a cooperative mechanism. J Biol Chem 260:6788-6800.

Lei S, Jackson MF, Jia Z, Roder J, Bai D, Orser BA, MacDonald JF (2000) Cyclic GMP-dependent feedback inhibition of AMPA receptors is independent of PKG. Nat Neurosci 3:559-565.

Leinders-Zufall T, Zufall F (1995) Block of cyclic nucleotide-gated channels in salamander olfactory receptor neurons by the guanylyl cyclase inhibitor LY83583. J Neurophysiol 74:2759-2762.

Leinders-Zufall T, Rosenboom H, Barnstable CJ, Shepherd GM, Zufall 
F (1995) A calcium-permeable cGMP-activated cation conductance in hippocampal neurons. NeuroReport 6:1761-1765.

Leinders-Zufall T, Rand MN, Shepherd GM, Greer CA, Zufall F (1997) Calcium entry through cyclic nucleotide-gated channels in individual cilia of olfactory receptor cells: spatiotemporal dynamics. J Neurosci 17:4136-4148.

MacVicar BA, Dudek FE (1980) Local synaptic circuits in rat hippocampus: interactions between pyramidal cells. Brain Res 184:220-223.

McLatchie LM, Matthews HR (1992) Voltage-dependent block by L-cisdiltiazem of the cyclic GMP-activated conductance of salamander rods. Proc R Soc Lond B Biol Sci 247:113-119.

McLatchie LM, Matthews HR (1994) The effect of $\mathrm{pH}$ on the block by L-cis-diltiazem and amiloride of the cyclic GMP-activated conductance of salamander rods. Proc R Soc Lond B Biol Sci 255:231-236.

Nicol GD, Schnetkamp PP, Saimi Y, Cragoe EJ, Bownds MD (1987) A derivative of amiloride blocks both the light-regulated and cyclic GMPregulated conductances in rod photoreceptors. J Gen Physiol 90:651-669.

Palmieri C, Kawasaki H, Avoli M (2000) Topiramate depresses carbachol-induced plateau potentials in subicular bursting cells. NeuroReport 11:75-78.

Parent A, Schrader K, Munger SD, Reed RR, Linden DJ, Ronnett GV (1998) Synaptic transmission and hippocampal long-term potentiation in olfactory cyclic nucleotide-gated channel type 1 null mouse. J Neurophysiol 79:3295-3301.

Pedarzani P, Krause M, Haug T, Storm JF, Stuhmer W (1998) Modu- lation of the $\mathrm{Ca}^{2+}$-activated $\mathrm{K}^{+}$current sIAHP by a phosphatasekinase balance under basal conditions in rat CA1 pyramidal neurons. J Neurophysiol 79:3252-3256.

Stern JH, Kaupp UB, MacLeish PR (1986) Control of the lightregulated current in rod photoreceptors by cyclic GMP, calcium, and L-cis-diltiazem. Proc Natl Acad Sci USA 83:1163-1167.

Traub RD, Miles R, Wong RK (1989) Model of the origin of rhythmic population oscillations in the hippocampal slice. Science 243:1319-1325.

Trivedi B, Kramer RH (1998) Real-time patch-cram detection of intracellular cGMP reveals long-term suppression of responses to NO and muscarinic agonists. Neuron 21:895-906.

Wei JY, Roy DS, Leconte L, Barnstable CJ (1998) Molecular and pharmacological analysis of cyclic nucleotide-gated channel function in the central nervous system. Prog Neurobiol 56:37-64.

Wotta DR, Parsons AM, Hu J, Grande AW, El-Fakahany EE (1998) M1 muscarinic receptors stimulate rapid and prolonged phases of neuronal nitric oxide synthase activity: involvement of different calcium pools. J Neurochem 71:487-497.

Zagotta WN, Siegelbaum SA (1996) Structure and function of cyclic nucleotide-gated channels. Annu Rev Neurosci 19:235-263.

Zhuo M, Hu Y, Schultz C, Kandel ER, Hawkins RD (1994) Role of guanylyl cyclase and cGMP-dependent protein kinase in long-term potentiation. Nature 368:635-639.

Zufall F, Shepherd GM, Barnstable CJ (1997) Cyclic nucleotide gated channels as regulators of CNS development and plasticity. Curr Opin Neurobiol 7:404-412. 